\title{
Development and validation of an analytical method for determination of ergot alkaloids in animal feedingstuffs with high performance liquid chromatography-fluorescence detection
}

\author{
E. Kowalczyk, E. Patyra, A. Grelik, K. Kwiatek \\ Department of Hygiene of Animal Feedingstuffs, National Veterinary Research Institute, \\ Partyzantów 57, 24-100 Puławy, Poland
}

\begin{abstract}
A high performance liquid chromatography combined with fluorescence detection (HPLC-FLD) method was developed for determination of five ergot alkaloids (EA): ergometrine, ergotamine, ergocornine, ergocrypine and ergocristine in animal feedingstuffs. The method was based on the application of QuEChERS salts for extraction and modified QuEChERS dispersive SPE for the cleanup step. Alkaloids separation was performed on a C18, $250 \mathrm{~mm}$ x $4.6 \mathrm{~mm}, 5 \mu \mathrm{m}$ column with the mobile phase containing ammonium carbonate and acetonitrile. The excitation and emission wavelengths were 330 and $420 \mathrm{~nm}$ respectively. The method was validated according to the Commission Decision 2002/657/EC and all parameters are in agreement with the requirements of the Decision. Linearity was determined for the concentration range of $25-400 \mu \mathrm{g} / \mathrm{kg}$. The coefficient of determination $\left(\mathrm{R}^{2}\right)$ for all curves was from 0.985 to 0.996 . The limit of detection (LOD) was in the range 3.23 to $6.53 \mu \mathrm{g} / \mathrm{kg}$ and the limit of quantification (LOQ) from 11.78 to $13.06 \mu \mathrm{g} / \mathrm{kg}$. The decision limit (CC $\alpha$ ) ranged from 29.56 to $43.08 \mu \mathrm{g} / \mathrm{kg}$ and detection capability (CC $\beta)$ from 40.65 to $51.01 \mu \mathrm{g} / \mathrm{kg}$. The highest coefficient of variation (CV) for repeatability was $14.3 \%$ and for reproducibility $15.4 \%$.
\end{abstract}

Key words: ergot alkaloids, feedingstuff, QuEChERS, HPLC-FLD

\section{Introduction}

The term ergot refers to fungal structures from Claviceps species replacing kernels on grain ears or seeds on grass heads, being visible as large discoloured sclerotia. The most widespread Claviceps species in Europe, Claviceps purpurea, is known to infect more than 400 plant species including main cereals such as rye, wheat, triticale, barley and rarely oats (Haarmann et al. 2009, EFSA 2012). The sclerotia are harvested with the grain, seed or grass and may result in EA contamination of cereal products and feedingstuffs (Storm et al. 2008).

Correspondence to: E. Kowalczyk, e-mail: ewelina.kowalczyk@piwet.pulawy.pl 
A)<smiles>[R]C(=O)[C@@H]1C=C2c3cccc4[nH]cc(c34)C[C@H]2N(C)C1</smiles>

Alkanolamides
B)<smiles>[R]C1C(=O)N2CCC[C@]2(O)[C@@]2(O)O[C@]([R])(NC(=O)[C@@H]3C=C4c5cccc6[nH]cc(c56)C[C@@H]4N(C)C3)C(=O)N12</smiles>

Ergopeptides

\begin{tabular}{ccccc}
\hline Compound & Type & Moiety R & Moiety $\mathrm{R}_{1}$ & Moiety $\mathrm{R}_{2}$ \\
\hline Ergometrine & Alkanolamide & $\mathrm{NHCH}\left(\mathrm{CH}_{3}\right) \mathrm{CH}_{2} \mathrm{OH}$ & - & - \\
\hline Ergotamine & Ergopeptide & & $\mathrm{CH}_{3}$ & $\mathrm{CH}_{2} \mathrm{C}_{6} \mathrm{H}_{5}$ \\
\hline Ergocornine & Ergopeptide & & $\mathrm{CH}\left(\mathrm{CH}_{3}\right)_{2}$ & $\mathrm{CH}_{\left(\mathrm{CH}_{3}\right)_{2}}$ \\
\hline Ergokryptine & Ergopeptide & $\mathrm{CH}\left(\mathrm{CH}_{3}\right)_{2}$ & $\mathrm{CH}_{2} \mathrm{CH}_{\left(\mathrm{CH}_{3}\right)_{2}}$ \\
\hline Eegocristine & Ergopeptide & $\mathrm{CH}\left(\mathrm{CH}_{3}\right)_{2}$ & $\mathrm{CH}_{2} \mathrm{C}_{6} \mathrm{H}_{5}$
\end{tabular}

Fig. 1. Chemical structure of the ergot alkaloids (Bryła et al. 2015).

In history there have been many cases of ergot intoxications or ergotism. It often occurred in epidemic form due to ingestion of rye contaminated with the ergot fungus. The disease, known in the Middle Ages as „St. Anthony's fire” was characterised by an extreme burning sensation in the extremities, and eventually gangrene leading to loss of the afflicted body parts (Flieger et al. 1997).

Currently, modern grain cleaning techniques have eliminated ergotism as a human disease, but it remains a significant disease in the veterinary field (Di Mavungu et al. 2012, Craig et al. 2015)

Ergot alkaloids exert toxic effects in all animal species, and the most prominent toxic signs can be attributed to the interaction of ergot alkaloids with adrenergic, serotinergic and dopaminergic receptors (EFSA 2005). EAs also have a number of well-established effects on the reproductive process, including prevention of pregnancy by interfering with implantation, embryotoxicity, developmental effects and inhibition of lactation. There is also some evidence of inhibition of ovulation (EFSA 2012).

Ergot is listed as an undesirable substance in animal feed within European Union Directive 2002/32/EC, and the maximum content of rye ergot in feedingstuffs containing unground cereals has been limited to $0.1 \%(1000 \mathrm{mg} / \mathrm{kg})$ (European Union
Directive 2002/32/EC, Ruhland and Tischler 2008). The risk of ergotism in livestock as a result of consuming contaminated cereal grains, or compound feeds manufactured from them, can be reduced when appropriate seed cleaning of grains is carried out (EFSA 2012). However, commonly used physical determination of the contamination rate of cereals by rye ergot is often inaccurate, as size and weight of the sclerotia may vary considerably. Moreover, this physical determination is impossible in processed feed and food (European Commission. 2012/154/EU). Currently, no maximum permissible levels (MPLs) of ergot alkaloids in grain and/or cereals have been set in the EU, whereas regulations in Switzerland specify that the level in cereals is $100 \mu \mathrm{g} / \mathrm{kg}$ (Bryła et al. 2015).

In 2012 the Commission Recommendation on the monitoring of the presence of ergot alkaloids in feed and food was published. According to the Recommendation it is necessary to generate more data on the presence of ergot alkaloids, not only in unground cereals but also in cereal products and compound feed and food and to obtain reliable data on the ergot alkaloid pattern in feed and food (European Commission 2012/154/EU).

Thus, it is important to develop reliable methods for the determination of ergot alkaloids that could be introduced to laboratory practice and effectively 
implemented in the Plan of Official Control of Feedingstuffs. For this reason the aim of this study was the development of simple analytical method based on high performance liquid chromatography combined with fluorescence detector (HPLC-FLD) which will enable determination of the ergot alkaloids: ergometrine, ergotamine, ergocornine, ergocrypine and ergocristine (Fig. 1) in feedingstuffs.

\section{Materials and Methods}

\section{Chemicals and reagents}

Acetonitrile of HPLC gradient grade was purchased from J.T. Baker (the Netherlands). 25\% aqueous ammonia, magnesium sulphate and sodium citrate were purchased from POCh (Poland). Sodium hydrogen citrate sesquihydrate, sodium chloride, ammonium carbonate, dispersive SPE sorbent PSA (primary secondary amine) and activated carbon were from Sigma Aldrich (Germany). Dichloromethane was from Merck (Germany), pure water was from a Milli-Q water purification system.

Crystalline standards of the ergot alkaloids: ergotamine, ergometrine, ergocornine, ergocristine, ergocryptine were purchased from Alfarma (Prague, Czech Republic).

\section{Instrumentation and chromatographic conditions}

The HP 1200 Series separation modules from Agilent Technologies (Santa Clara, CA, USA) equipped with a degasser system, automatic injector, binary pump, column thermostat and fluorescence detector was used for the performance of the analysis. The separation was carried on a Luna C18, $250 \mathrm{~mm}$ x 4.6 $\mathrm{mm}, 5 \mu \mathrm{m}$ column, Phenomenex, (USA) at $25^{\circ} \mathrm{C}$. The mobile phase containing a mixture $(50: 50, \mathrm{v} / \mathrm{v})$ of $2 \mathrm{mM}$ ammonium carbonate (A) and acetonitrile (B) was used in a gradient mode as follows (time, $\% \mathrm{~B}$ ): $0 \mathrm{~min}, 21 \%$; $1 \mathrm{~min}, 38 \%$; $4.8 \mathrm{~min}, 50 \%$; $23 \mathrm{~min}, 50 \%$; $25 \mathrm{~min}, 100 \%$; $28 \mathrm{~min}, 100 \%$; $30 \mathrm{~min}, 21 \%$ and hold for $4 \mathrm{~min}$. The flow was $1 \mathrm{~mL}$ for $1 \mathrm{~min}, 0.7 \mathrm{~mL} / \mathrm{min}$ from 4.8 to $10 \mathrm{~min}, 0.9 \mathrm{~mL} / \mathrm{min}$ from 10 to $14 \mathrm{~min}$, $1 \mathrm{~mL} / \mathrm{min}$ from 14 to $20 \mathrm{~min}, 0.8 \mathrm{~mL} / \mathrm{min}$. from 20 to $23 \mathrm{~min}$, and $1 \mathrm{~mL} / \mathrm{min}$ from 25 to $34 \mathrm{~min}$.

The detection was carried with the fluorescence detector, the excitation and emission wavelengths were $330 \mathrm{~nm}$ and $420 \mathrm{~nm}$, respectively and the injection volume was $100 \mu \mathrm{L}$.

\section{Sample preparation}

$5 \mathrm{~g}$ of milled and sieved feed sample was weighed in a $50 \mathrm{~mL}$ polypropylene tube. $20 \mathrm{~mL}$ of dichloromethane, $5 \mathrm{~mL}$ of acetonitrile, $0.5 \mathrm{~mL}$ of $25 \%$ ammonia solution and a mixture of QuEChERS salts containing $0.5 \mathrm{~g}$ of sodium chloride, $4 \mathrm{~g}$ of magnesium sulphate, $0.25 \mathrm{~g}$ of sodium hydrogen citrate sesquihydrate and $0.5 \mathrm{~g}$ of sodium citrate were added. The sample was shaken on horizontal shaker for $30 \mathrm{~min}$. The mixture was centrifuged and the supernatant was transferred to a new polypropylene tube containing $1 \mathrm{~g}$ of magnesium sulphate, $0.4 \mathrm{~g}$ of dispersive sorbent PSA and $0.08 \mathrm{~g}$ of activated carbon. The tube was shaken for $20 \mathrm{~min}$. centrifuged, filtered and evaporated to dryness under a nitrogen stream. The residue was reconstituted in $0.4 \mathrm{~mL}$ of mobile phase (acetonitrile: $2 \mathrm{mM}$ ammonium carbonate, 50:50, v/v) and passed through a $0.45 \mu \mathrm{m}$ nylon syringe filter and subjected to instrumental analysis.

\section{Method validation}

The procedure was validated in-house according to Commission Decision 2002/657/EC. Parameters such as method linearity, limits of detection (LODs), limits of quantification (LOQs), repeatability, within-laboratory reproducibility, recovery, specificity, decision limit $(\mathrm{CC} \alpha)$ and detection capability $(\mathrm{CC} \beta)$ were evaluated. The method was validated for ergomertrine, ergotamine, ergocornine, ergocryptine and ergocristine.

For determination of the linearity of the method, blank feed samples were spiked with ergot alkaloids at appropriate concentrations, ranging from 25 to 400 $\mu \mathrm{g} / \mathrm{kg}$ and the analysis was performed in triplicate. The coefficient of determination and curve equations were calculated and the results are listed in Table 1.

Selectivity of the method was determined by analysis of a set of blank feed samples and the absence of interfering peaks in retention times corresponding to the particular alkaloid. The same set of blank samples was used for the calculation of limit of detection (LOD) and limit of quantification (LOQ) with the equations: $x+3 *$ SD for LOQ and $x+k * S D$ for LOD, where $x$ is the average concentration of the analyte in the sample, calculated on the basis of the calibration curve, and SD is the standard deviation of the calculated concentration, $\mathrm{k}-6$ or 10 .

Blank feed samples spiked at concentration levels 25,150 and $400 \mu \mathrm{g} / \mathrm{kg}$ (six replicates for each concentration) were used to evaluate the method's recovery and repeatability. The samples were analysed with the same instrument and the same operator. For determi- 
Table 1. Method validation data: linearity parameters, limit of detection (LOD), limit of quantification (LOQ), decision limit $(\mathrm{CC} \alpha)$ and detection capability $(\mathrm{CC} \beta)$.

\begin{tabular}{ccccc}
\hline \multirow{2}{*}{ Ergot alkaloid } & \multicolumn{2}{c}{ Linearity } & LOD $/ \mathrm{LOQ}$ & $\mathrm{CC} / \mathrm{CC} \beta$ \\
\cline { 2 - 5 } & Equation & $\mathrm{R}^{2}$ & $(\mu \mathrm{g} / \mathrm{kg})$ \\
\hline Ergometrine & $\mathrm{Y}=2.116 \mathrm{x}-11.53$ & 0.990 & $8.79 / 11.02$ & $39.74 / 48.28$ \\
\hline Ergotamine & $\mathrm{Y}=2.285 \mathrm{x}-23.41$ & 0.992 & $3.23 / 6.53$ & $29.56 / 43.71$ \\
\hline Ergocornine & $\mathrm{Y}=4.091 \mathrm{x}-0.848$ & 0.996 & $5.38 / 8.09$ & $43.08 / 51.01$ \\
\hline Ergocryptine & $\mathrm{Y}=4.235 \mathrm{x}-29.62$ & 0.993 & $5.58 / 7.73$ & $34.31 / 41.58$ \\
\hline Ergocristine & $\mathrm{Y}=2.145 \mathrm{x}+4.04$ & 0.985 & $11.78 / 13.06$ & $34.53 / 40.65$ \\
\hline
\end{tabular}

Table 2. Method validation data: recovery, CVs of repeatability and reproducibility.

\begin{tabular}{ccccc}
\hline Ergot alkaloid & $\begin{array}{c}\text { Concentration level } \\
(\mu \mathrm{g} / \mathrm{kg})\end{array}$ & $\begin{array}{c}\text { Recovery } \\
(\%)\end{array}$ & $\begin{array}{c}\text { Repeatability } \\
\text { CV }(\%)\end{array}$ & $\begin{array}{c}\text { Reproducibility } \\
\text { CV }(\%)\end{array}$ \\
\hline \multirow{3}{*}{ Ergometrine } & 25 & 100.9 & 9.3 & 13.6 \\
& 150 & 94.8 & 14.8 & 9.9 \\
& 400 & 108.5 & 5.0 & 7.1 \\
\hline \multirow{2}{*}{ Ergotamine } & 25 & 91.6 & 14.2 & 15.4 \\
& 150 & 104.7 & 12.4 & 14.6 \\
\hline \multirow{2}{*}{ Ergocornine } & 400 & 99.9 & 10.5 & 10.3 \\
& 25 & 108.4 & 9.0 & 11.3 \\
& 150 & 86.6 & 11.9 & 12.0 \\
\hline \multirow{2}{*}{ Ergocryptine } & 400 & 102.4 & 9.0 & 9.1 \\
& 25 & 99.4 & 6.5 & 9.9 \\
Ergocristine & 150 & 89.7 & 6.2 & 8.0 \\
& 400 & 94.7 & 8.5 & 11.1 \\
\end{tabular}

nation of within-laboratory reproducibility, two other sets of samples were spiked at the same concentrations as for repeatability, and analysed on different days with the same instrument and a different operator. The precision of the method (for repeatability and reproducibility) was calculated as coefficient of variation $(\mathrm{CV})$.

For calculation of the decision limit $(\mathrm{CC} \alpha)$ and detection capability (CC $\beta$ ) the matrix calibration curve procedure was used. $\mathrm{CC} \alpha$ and $\mathrm{CC} \beta$ were calculated with the statistical certainty of $1-\alpha(\alpha=0.05)$ and $1-\beta(\beta=0.05)$ respectively.

\section{Results}

The new method for determination of ergot alkaloids was developed, and subsequently validated in-house, according to Commission Decision 2002/657/EC requirements. The validation parameters were established and are presented in Tables 1 and 2 . Quantification was based on matrix calibration curves.
Calibration curves for all alkaloids were linear in a concentration range of $25-400 \mu \mathrm{g} / \mathrm{kg}$. The coefficient of determination $\left(\mathrm{R}^{2}\right)$ for all curves ranged from 0.985 to 0.996 . The lowest LOD and LOQ values were obtained for ergotamine and were 3.23 and $6.53 \mu \mathrm{g} / \mathrm{kg}$ respectively, and the highest for ergocristine at 11.78 and $13.06 \mu \mathrm{g} / \mathrm{kg}$. CC $\alpha$ ranged from 29.56 to 43.08 $\mu \mathrm{g} / \mathrm{kg}$ and CC $\beta$ from 40.65 to $51.01 \mu \mathrm{g} / \mathrm{kg}$ (Table 1 ).

Precision of the method was evaluated by intra and inter-day analysis of spiked blank feed samples with appropriate concentrations (25, 150 and 400 $\mu \mathrm{g} / \mathrm{kg}$ ) of five ergot alkaloids. For the assessment of repeatability the analysis of six spiked samples at each concentration level was performed within one day and was in the range of 5.0 to $14.3 \%$. For the reproducibility estimation another two sets of spiked samples at the same concentration level as for repeatability were analyzed on different days and the values were from 7.1 to $15.4 \%$.

The recovery data (Table 2 ), were obtained for concentration levels 25,150 and $400 \mu \mathrm{g} / \mathrm{kg}$, and the values are within 86.6 to $108.5 \%$ interval. 


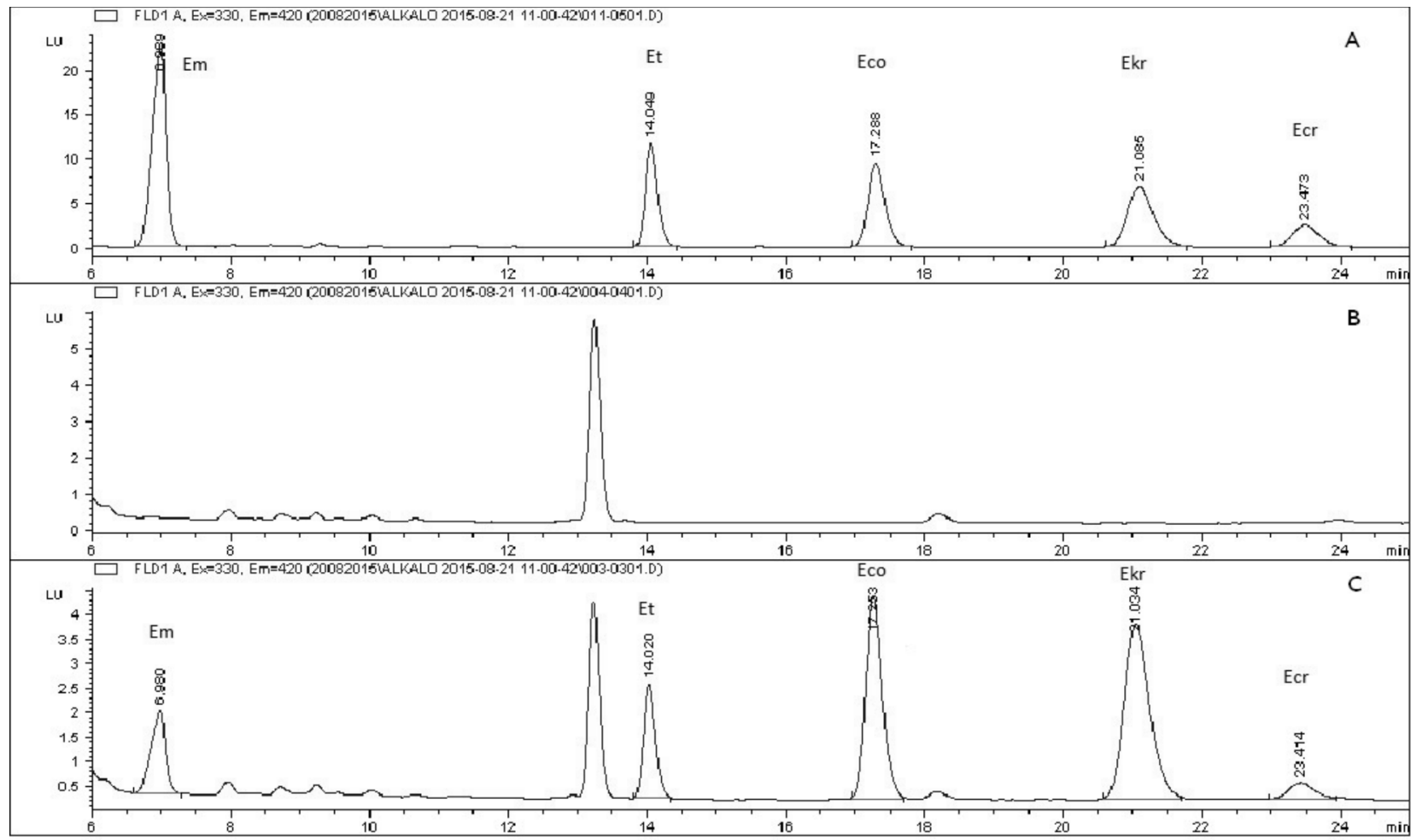

Fig. 2. Chromatograms of ergot standards (A), blank matrix sample (B) and sample spiked with five ergot alkaloids at a concentration level of $25 \mu \mathrm{g} / \mathrm{kg}$ (C). Em - ergometrine, Et - ergotamine, Eco - ergocornine, Ekr - ergocryptine, Ecr - ergocristine.

Chromatograms of ergot standards, blank sample and sample spiked with five ergot alkaloids are presented in Fig. 2.

\section{Discussion}

The article presents a new approach for the determination of five ergot alkaloids: ergotamine, ergometrine, ergocornine, ergocryptine and ergocristine, the most prevalent in compound feeds. The aim was to develop a procedure based on QuEChERS salts, as they are used in the analysis of many compounds such as pesticides, other mycotoxins or pyrrolizidine alkaloids. Magnesium sulphate combined with sodium chloride was already presented in an application for ergovaline determination in tall fescue seeds and straw (Walker et al. 2015). However, this composition of salts was not sufficient for a feddingstuff matrix. For this reason, it was decided to use other ingredients such as sodium hydrogen citrate sesquihydrate, sodium citrate, and the combination of magnesium sulphate and sodium acetate. It became apparent that the best results were obtained for simultaneous use of magnesium sulphate, sodium chloride, sodium hydrogen citrate sesquihydrat and sodium citrate.

For an additional cleanup step dispersive sorbent PSA was tested. PSA is a weak anion exchange sorbent with the ability to remove fatty acids, sugars and other matrix co-extractives that form hydrogen bonds. The PSA sorbent was used as a single purification agent during ergot alkaloids analysis with LC MS/MS (Krska et al. 2008). However, for the HPLC-FLD, additional agents had to be employed because many impurities were still present in the extract, and therefore magnesium sulphate and activated carbon (AC) were added. Usually in the composition of QuEChERS dispersive SPE cleanup set graphitized carbon black (GBC) is used. It was noticed that activated carbon was an efficient but inexpensive alternative to GCB. Activated carbon is a carbonaceous skeleton with a large network of pores and it is these pores that trap organic contaminants, mainly by adsorption. It was observed that except for pigments, a certain amount of fat content was also eliminated from the extract. However, a large increase in the amount of activated carbon is not recommended as it led to poor recovery of the alkaloids, especially ergometrine and ergotamine.

Ergot alkaloids are positively charged at N-6 in acidic solutions and neutral at higher $\mathrm{pH}$. This is why they can be extracted either with non-polar organic solvents under alkaline conditions or with polar solvents under acidic conditions (Krska and Crews 2008, Di Mavungu et al. 2012). During method development many combinations of extraction solvents were 
used. Some of them have already been reported by other authors such as the mixture of dichloromethane/ethyl acetate/methanol/25\% ammonium (Müller et al. 2009) or acetonitrile/ammonium carbonate (Bryła et al. 2015); however, in combination with QuEChERS they did not give acceptable results as far as the recovery and amount of co-extractive compounds are concerned. For this reason a new solvents combination was selected and the mixture contained $20 \mathrm{~mL}$ of dichloromethane, $5 \mathrm{~mL}$ of acetonitrile and $0.5 \mathrm{~mL}$ of $25 \%$ ammonium. This proportion of solvents was chosen as the optimal combination for ergot alkaloids extraction. The increase in acetonitrile volume resulted in improved signal intensity of ergometrine as it is a relatively more polar alkaloid (Di Mavungua et al. 2012) but increased the impurity rate as well. No significant differences were observed when the volume of ammonium solution was decreased or increased.

For the separation of ergot alkaloids most authors used reverse phase C18 columns (Mohamed et al. 2006, Storm et al. 2008, Di Mavungu et al. 2012) though, the separation was also performed on a C6 phenyl column (Muller et al. 2009). As far as the mobile phase is concerned, the most popular composition was ammonium carbonate at different concentrations and acetonitrile (Storm et al. 2008, Muller et al. 2009, Bryła et al. 2015) used in an isocratic and gradient mode as well. In the presented method the separation was also performed on a C18 column with the mobile phase consisted of ammonium carbonate and acetonitrile; however, a gradient mode was used which provided good separation of ergot alkaloids, and method selectivity.

Ergot alkaloids are light sensitive and degrade or undergo isomerization under ultraviolet light radiation. However, many of the alkaloids, including the most prevalent ones, are naturally fluorescent, and this property is often used for detection (Krska and Crews 2008, Storm et al. 2008). Excitation wavelengths are often in the range 235-250 nm (Krska and Crews 2008) which provides high sensitivity for the method; though, this range is not sufficiently selective and many other interfering compounds were also detected. For this reason $330 \mathrm{~nm}$ and $420 \mathrm{~nm}$ were chosen as the excitation and emission wavelengths respectively, thanks to which some impurities were avoided.

A new method for the determination of chosen ergot alkaloids in animal feedingstuff was developed. The method was based on modified QuEChERS and liquid chromatography with FLD, which provided an easy procedure for sample preparation and instrumental analysis. The method was validated according to Commission Decision 2002/657/EC and all parameters are in agreement with the requirements of the Decision. The method can be easily implemented in the laboratory practice or extended for related -inines of the presented alkaloids.

\section{Reference}

Bryła M, Szymczyk K, Jędrzejczak R, Roszko M (2015) Application of Liquid Chromatography/Ion Trap Mass Spectromery Technique to Determine Ergot Alkaloids in Grain Products. Food Technol Biotechnol 53: 16-26.

Craig AM, Klotz JL, Duringer JM (2015) Cases of ergotism in livestock and associated ergot alkaloid concentrations in feed. Front Chem 3: 1-6.

Crews C (2015) Analysis of Ergot Alkaloids. Toxins 7: 2024-2050

Di Mavungu JD, Malysheva SV, Sanders M, Larionova D, Robbens J, Dubruel P, Van Peteghem C, De Saeger $S$ (2012) Development and validation of a new LC-MS/MS method for the simultaneous determination of six major ergot alkaloids and their corresponding epimers. Application to some food and feed commodities. Food Chem 135: 292-303.

Directive 2002/32/EC of the European Parliament and of the Council of 7 May 2002 on undesirable substances in animal feed. http://eur-lex.europa.eu/LexUriServ/LexUri Serv.do? uri=CONSLEG:2002L0032:20100302:EN:PDF

European Commission. 2012/154/EU: Commission recommendation of 15 March 2012 on the monitoring of the presence of ergot alkaloids in feed and food http://eur-lex.europa.eu/legal-content/EN/TXT/PDF/?uri $=$ CELEX:32012H0154\&from $=$ PL

European Food Safety Authority (EFSA) (2005) Opinion of the Scientific Panel on Contaminants in Food Chain on a request from the Commission related to ergot as undesirable substance in animal feed. EFSA J 225: 1-27.

European Food Safety Authority (EFSA), Panel on Contaminants in the Food Chain (CONTAM) (2012) Scientific Opinion on Ergot alkaloids in food and feed. EFSA J 2798: 1-158.

Flieger M, Wurst M, Shelby R (1997) Ergot Alkaloids - Sources, Structures and Analytical Methods. Folia Microbiol 42: 3-29.

Haarmann T, Rolke Y, Giesbert S, Tudzynski P (2009) Ergot: from witchcraft to biotechnology. Mol Plant Pathol 10: 563-577.

Krska R, Crews C (2008) Significance, chemistry and determination of ergot alkaloids: a review. Food Addit Contam A 25: 722-731.

Krska R, Stubbings G, Macarthur R, Crews C (2008) Simultaneous determination of six major ergot alkaloids and their epimers in cereals and foodstuffs by LC-MS-MS. Anal Bioanal Chem 391: 563-576.

Mohamed R, Gremaud E, Richoz-Payot J, Tabet JC, Guy PA (2006) Quantitative determination of five ergot alkaloids in rye flour by liquid chromatography-electrospray ionisation tandem mass spectrometry. J Chromatogr A 1114: 62-72.

Muller C, Kemmlein S, Klaffke H, Krauthause W, Preiss-Weigert A, Wittkowski R (2009) A basic tool for risk assessment: a new method for the analysis of ergot alkaloids in rye and selected rye products. Mol Nutr Food Res 53: 500-507. 
Ruhland M, Tischler J (2008) Determination of ergot alkaloids in feed by HPLC. Mycotoxin Res 24: 73-79.

Storm ID, Rasmussen PH, Strobel BW, Hansen HC (2008)

Ergot alkaloids in rye flour determined by solid-phase cation-exchange and high-pressure liquid chromatography with fluorescence detection. Food Addit Contam A 25: 338-346.
Walker K, Duringer J, Craig AM (2015) Determination of the Ergot Alkaloid Ergovaline in Tall Fescue Seed and Straw Using a QuEChERS Extraction Method with High-Performance Liquid Chromatography-Fluorescence Detection. J Agric Food Chem 63: 4236-4242. 